\title{
Impact of Planned Teaching Program on Staff Nurses Regarding Prevention of Urinary Tract Infection
}

\author{
Mukesh Singh ${ }^{1}$, Sunil Kumar ${ }^{2}$ and Shatrughan Pareek ${ }^{3 *}$ \\ ${ }^{1}$ Assistant Professor, Medical Surgical Nursing, Quadra Institute of Nursing, Roorkee, Uttarakhand, India \\ ${ }^{2}$ Nursing Incharge and CCN Trainer, Bhagwan Mahaveer Cancer Hospital and Research Centre, Jaipur, Rajasthan, India \\ ${ }^{3}$ Nursing Superintendent, Indian Railway Health Services, Bikaner, Rajasthan, India
}

*Corresponding author: Shatrughan Pareek, Nursing Superintendent, Indian Railway Health Services, Bikaner, Rajasthan, India; E-mail: shatrughan.pareek@gmail.com

Received: September 07, 2021; Accepted: September 14, 2021; Published: September 25, 2021

\begin{abstract}
Introduction: Application of indwelling catheter can ' lead to complications. Most commonly catheter is associated with urinary tract infections. Duration of catheterization is the major risk factor. The present study was conducted with aim to evaluate the effectiveness of planned teaching program in terms of knowledge of staff nurses regarding prevention of urinary tract infection in patients with indwelling catheter.
\end{abstract}

Methodology: Quantitative research approach and quasi-experimental design with one group pre-test and post-test were adopted for the study. The study was carried out among 60 staff nurses at B.M.C.H.R.C., Hospital, Jaipur.

Results: The findings highlighted that during pre-test, majority of the nurses (83\%) having average knowledge while after implementation of PTP, most of the nurses $(86 \%)$ have good level of knowledge regarding prevention of UTI. Pre-test knowledge score was $13.50 \pm 3.735$ and posttest knowledge score was $23.32 \pm 4.446$. The obtained value (11.742) was higher than the tabulated value (1.97), which indicates that intervention was significant at 0.05 level of significance.

Conclusion: Pre-test findings showed that knowledge of nurses regarding prevention of UTI was average. While, the administration of Plan teaching program helped the staff nurses to understand more regarding prevention of UTI infection.

Keywords: Effectiveness, Planned teaching program, Knowledge, Staff nurses, Prevention of UTI

\section{Introduction}

Understanding the different classifications of UTIs is necessary when considering their epidemiology. Broadly, UTIs are classified based on their location in the urinary tract, the presence of relevant complicating factors, and the presence or absence of symptoms [1]. A urinary tract infection (UTI) is a bacterial infection that affects any part of the urinary tract. The main etiologic agent is Escherichia coli. Although urine contains a variety of fluids, salts, and waste products, it does not usually have bacteria in it. When bacteria gets into the bladder or kidney and multiply in the urine, they may cause a UTI [2]. Bladder infections are most common in young women with $10 \%$ of women getting an infection yearly and $60 \%$ having an infection at some point in their life. Pyelonephritis occurs between 18-29 times less frequently [3]. Urinary tract infection are most common nosocomial infection. Responsible for $20-30 \%$ of nosocomial infection in medical or surgical intensive care unit. The overall incidence density of ICU nosocomial UTI as high $32 \%, 17 \%$ those in medical ward or $9 \%$ in rehabilitation unit, 7\% in nursing home. catheter acquired UTI is one of the most common health care acquired infection $70-80 \%$ of these infection are attributable to use of an indwelling urethral catheter [4]. One of the most common types of hospital-acquired infection is urinary tract infection (UTI), accounting for more than $40 \%$ of all nosocomial infections. Virtually, all health-care-associated UTIs (CAUTIs) are caused by instrumentation of the urinary tract. CAUTI has been associated with increased morbidity, mortality, hospital stay, and treatment cost. The daily risk of bacteriuria with catheterization is $3-10 \%$ [5]. Globally UTI is most common female infection accounting for an estimated 1.4 million cases each year with more than half of the 4.5 lakh UTI death occurring in low- and middle-income countries. UTI account $40 \%$ of all hospital acquired infection [6]. Use of indwelling catheter can lead to complications. Most commonly catheter is associated with urinary tract infections. Duration of catheterization is the major risk factor. These infections can result in sepsis, prolonged hospitalization, additional hospital costs and mortality [7]. Prevention starts with the health care provider, except in special circumstances, all urinary catheters should place in a sterile way. Insertion of non-sterile catheter or using a non-sterile technique is much more likely to result in a urinary tract infection.

\section{Methodology}

In the present study, quantitative research approach was adopted to conduct the study. Quasi-experimental design with one group pretest and post-test was selected for the research work. The study was carried out among 60 staff nurses at B.M.C.H.R.C., Hospital, Jaipur. After obtaining permission from concerned authority the pilot study 
was conducted from 01-07-2017 to 07-07-2017 at B.M.C.H.R.C. Jaipur. The samples choose were similar to population under study. The investigator used purposive sampling technique to select the samples from the total population. Structured knowledge questionnaire was developed for the study to collect the data from staff nurses to assess their knowledge regarding hand hygiene for prevention of infection in cancer patients. There were 30 questions in the questionnaire. A pre-test was conducted by administering questionnaire then it was followed by administering Plan Teaching Program on prevention of UTI. The pretest was administered for each staff nurses. On the $7^{\text {th }}$ day a post test was administered by using the same tool which was used in pre-test.

\section{Results}

As per Table 1, in gender wise distribution the majority (71.66\%) of the sample were female. In age wise distribution the majority $(38.10 \%)$ of sample belongs to the age group 31-40 years. Information acquired wise distribution reveals that most of sample (33.33\%) had knowledge during professional qualification. Formal education wise majority (40.00\%) of samples qualification was Post Basic B.Sc. Nursing. In working experience wise distribution, the majority (35\%) having age group 1-3 years experience. Infrequency of UTI patient in the ward wise the majority (41.66\%) belongs to ICU ward. One third of the participants have previous knowledge due to professional qualification. Table 2 revealed that the findings of the study reveal that during pre-test majority $15.00 \%$ knowledge is poor, $83 \%$ of samples having average knowledge regarding prevention of UTI. During post-

Table 1: Frequency and percentage distribution of demographic variables, $n=60$.

\begin{tabular}{|c|c|c|c|}
\hline Sample & & Frequency & Percentage \\
\hline & 21-30 years & 9 & $15.00 \%$ \\
\hline & $31-40$ years & 22 & $38.10 \%$ \\
\hline & 41-50 years & 18 & $29.90 \%$ \\
\hline & $>50$ years & 11 & $17.00 \%$ \\
\hline & Male & 17 & $28.33 \%$ \\
\hline & Female & 43 & $71.66 \%$ \\
\hline & GNM & 11 & $18.33 \%$ \\
\hline Professional & B Sc. Nursing & 20 & $33.33 \%$ \\
\hline Qualification & Post Basic B.Sc. Nursing & 24 & $40.00 \%$ \\
\hline & M.Sc. Nursing & 5 & $08.33 \%$ \\
\hline & 1-3 years & 26 & $35.00 \%$ \\
\hline Years of Experience in & 4-6 years & 15 & $26.66 \%$ \\
\hline hospital & 7-9 years & 15 & $26.00 \%$ \\
\hline & $>10$ years & 5 & $13.33 \%$ \\
\hline & Male Ward & 12 & $20.00 \%$ \\
\hline HI t & Female ward & 16 & $26.66 \%$ \\
\hline & ICU ward & 25 & $41.66 \%$ \\
\hline & Other's ward & 7 & $11.66 \%$ \\
\hline & Journals & 14 & $23.33 \%$ \\
\hline Previous source of & During professional qualification & 20 & $33.33 \%$ \\
\hline knowledge & Continuing nursing education & 16 & $26.66 . \%$ \\
\hline & Others sources & 10 & $16.66 \%$ \\
\hline
\end{tabular}

Table 2: Distribution of frequency and percentage of levels of knowledge regarding prevention of UTI, $n=60$.

\begin{tabular}{|l|c|c|c|c|}
\hline \multirow{2}{*}{ Level of knowledge } & \multicolumn{2}{|c|}{ Pre-test } & \multicolumn{2}{c|}{ Post-test } \\
\cline { 2 - 5 } & Frequency (N) & Percentage (\%) & Frequency (N) & Percentage (\%) \\
\hline Poor (0-35\%) & 9 & 15 & 0 & 00 \\
\hline Average (36-70\%) & 50 & 83 & 8 & 14 \\
\hline Good (71\% above) & 1 & 1.66 & 52 & 86 \\
\hline Total & 60 & 100.0 & 60 & 100.0 \\
\hline
\end{tabular}

Table 3: Compression of pre and post group on knowledge regarding prevention of UTI, $\mathrm{n}=60$.

\begin{tabular}{|l|l|c|c|c|c|c|c|}
\hline \multicolumn{2}{|l|}{ Knowledge } & Mean & $\begin{array}{c}\text { Std. } \\
\text { Deviation }\end{array}$ & $\begin{array}{c}\text { Std. Error } \\
\text { Mean }\end{array}$ & $\begin{array}{c}\text { Mean } \\
\text { Difference }\end{array}$ & $\begin{array}{c}\text { Parried } \\
\text { t-test }\end{array}$ & p-value \\
\hline \multirow{2}{*}{ Test } & Pretest & 13.50 & 3.735 & 0.482 & \multirow{2}{*}{9.82} & 11.742 & $<0.00001$ \\
\cline { 2 - 7 } & Posttest & 23.32 & 4.46 & 0.574 & & \\
\hline
\end{tabular}

(0.05 level of significance)

Table 4: Association between demographic variables and level of knowledge regarding prevention of UTI, $n=60$.

\begin{tabular}{|l|c|c|c|}
\hline Variables & $\begin{array}{c}\text { Calculated } \\
\text { Chi-Square value }\end{array}$ & $\begin{array}{c}\text { Tabulated } \\
\text { Chi-Square value }\end{array}$ & p-value \\
\hline Age & 0.663 & 3.84 & 0.995 \\
\hline Gender & 0.046 & 3.84 & 0.977 \\
\hline Professional Qualification & 6.70 & 5.99 & $\mathbf{0 . 0 3 5}$ \\
\hline Working Experience & 0.118 & 3.84 & 0.731 \\
\hline Working Area & 1.59 & 7.81 & 0.810 \\
\hline Previous Source of Knowledge & 7.98 & 7.81 & $\mathbf{0 . 0 4 6}$ \\
\hline
\end{tabular}

(0.05 level of significance)

test majority $86 \%$ of staff nurses knowledge level is good. Only $14 \%$ of staff nurses have average knowledge. According to Table 3, Pretest knowledge score was $13.50 \pm 3.735$ and posttest knowledge score was $23.32 \pm 4.446$. The obtained value (11.742) was higher than the tabulated value (1.97), which indicates that intervention was significant at .05 level of significance. As per date presented in Table 4, revealed that there is a not significant association between the knowledge of the prevention of UTI with their Age, gender, professional qualifications, years of experience and working area, as the calculated Chi-square value was less than the tabulated value. While Previous source of knowledge was significantly associated with UTI knowledge, as the calculated Chi-square value 7.98 was greater than the tabulated value 7.81 at $\mathrm{p}>0.05$ (Tables $1-4$ ).

\section{Discussion}

The insertion of an indwelling urethral urinary catheter is an invasive procedure that is commonly undertaken in healthcare settings ${ }^{7}$. However, there are several risks and potential complications associated with these devices, so their use should be avoided where possible. It is important that nurses are equipped with the necessary knowledge and skills not only to assess if a patient requires a catheter, but also to minimize the risk of associated complications and to understand how these can be managed. The present study was conducted with aim to evaluate the effectiveness of planned teaching program in terms of knowledge and practice of staff nurses regarding 
prevention of urinary tract infection in clients with indwelling catheter. The finding of the study reveals that during pre-test, majority of the nurses (83\%) having average knowledge while after implementation of PTP, most of the nurses (86\%) have good level of knowledge regarding prevention of UTI. In this context, Purbia Vijay et al (2014) stated that in pre-test out of 90 respondents only 26 respondents (28.88\%) belongs to adequate knowledge regarding prevention of urinary tract infection among patient with indwelling catheter. In post-test 60 (66.66\%) respondents belongs to moderate knowledge and 30(33.33 $\%$ respondents belongs to adequate knowledge [8]. In another study, Ranjita Jena et al (2020) stated that most of the nurses (61.2\%) average knowledge towards prevention of UTI among patients with an indwelling catheter [9]. In this contrast, present study explored that $62.1 \%$ nurses had average knowledge towards prevention of UTI. Jicy Shahji indicated that the staff nurses knowledge on catheter associated urinary tract infections was not adequate [10]. In different study, Atul Sharma et al revealed that the mean post-test knowledge score (21.53) was higher than the mean pre-test score (11.13). Similarly in our study, pre-test knowledge score was $13.50 \pm 3.735$ and posttest knowledge score was $23.32 \pm 4.446$ [11]. Additionally, in our study the obtained t-test value (11.742) was higher than the tabulated t-test value (1.97), which indicates that the intervention was significantly effective at .05 level of significance. In this support, Purbia Vijay et al highlighted that mean score of post-test knowledge 21.53 was apparently higher than the mean score of pre-test knowledge 13.51, suggesting that the planned teaching program was effective in increasing the knowledge of the staff nurses regarding prevention of urinary tract infection among patients with indwelling catheter [8]. In another study, Atul Sharma et al highlighted that the mean difference pre-test score (8.02) of knowledge of significant at $0.05 \%$ level at the " $\mathrm{t} "=17.06$. $\mathrm{p}$ value 0.05 . This indicates the planned teaching program was effective in increasing the knowledge of staff nurses on the prevention of UTIs among patient with an indwelling catheter [11]. This finding was in support of our research finding. Furthermore, Jicy Shahji also communicated that structured teaching program on catheter associated urinary tract infections was significantly effective to increase the knowledge the knowledge of the staff nurses [10]. In context to association, the present study revealed that there was no significant association between the levels of knowledge of the prevention of UTI with their Age, gender, professional qualifications, years of experience and working area. While Previous source of knowledge was significantly associated with UTI knowledge, as the calculated Chi-square value 7.98 was greater than the tabulated value 7.81 at $\mathrm{p}>0.05$. There was no study available to compare the current findings. The intervention was effective to enhance the knowledge of nurses regarding prevention of UTI infection.

\section{Conclusion}

The present study concluded that the Pre-test findings showed that knowledge of nurses regarding prevention of UTI was average. While, the administration of Plan teaching program helped the staff nurses to understand more regarding prevention of UTI infection. Most of staff nurses were having good knowledge after administration of Plan teaching program. The Plan teaching program is proved to be very effective method of enhance knowledge.

\section{References}

1. Medina M, Castillo-Pino E (2019) An introduction to the epidemiology and burden of urinary tract infections. Ther Adv Urol 11. [crossref]

2. Flores-Mireles AL, Walker JN, Caparon M, Hultgren SJ (2015) Urinary tract infections: epidemiology, mechanisms of infection and treatment options. Nat Rev Microbiol 13: 269-284.

3. Minardi D, d'Anzeo G, Cantoro D, Conti A, Muzzonigro G (2011) Urinary tract infections in women: etiology and treatment options. Int J Gen Med 4: 333-343. [crossref]

4. Dasgupta S, Das S, Chawan NS, Hazra A (2015) Nosocomial infections in the intensive care unit: Incidence, risk factors, outcome and associated pathogens in a public tertiary teaching hospital of Eastern India. Indian J Crit Care Med 19: 14-20. [crossref]

5. Mudgal SK (2018) Assess the Effectiveness of Educational Program on Practice Regarding Indwelling Catheter Care among Staff Nurses at Selected Hospitals in Udaipur. Int J Nurs Med Invest 3: 89-91.

6. Foxman B (2002) Epidemiology of urinary tract infections: incidence, morbidity, and economic costs. Am J Med 113 Suppl 1A: 5S-13S. [crossref]

7. Nicolle LE (2014) Catheter associated urinary tract infections. Antimicrob Resist Infect Control 3.

8. Purbia V, Himanshu V, Maneesh KS, Devashri R (2014) A study to assess the effectiveness of planned teaching programme on knowledge of staff nurses regarding prevention of urinary tract infection among patients with indwelling catheter. Int $J$ Sci Res Pub 4: 1-5.

9. Ranjita Jena, Uma Mandal, Gurmanpreet Kaur, Suranjakhi Dash, Tiyasha Das (2020) Knowledge and practice of staff nurses on prevention of UTI among patients with an indwelling catheter in selected hospital Bhubaneswar. European J Mole Clin Med 7: $5070-5080$

10. Jicy Shahji (2016) A Study to Assess the Effectiveness of Structured Teaching Programme (STP) on Knowledge and Practice Regarding Indwelling Catheter Associated Urinary Tract Infection Among the Staff Nurses at J.K. Hospital And Research Center, Bhopal (M.P.). Int J Emerg Trauma Nurs 1: 5-16.

11. Atul Sharma Jitendra Sharma, Dinesh Kumar Sharma (2018) Effectiveness of planned teaching programme on knowledge regarding prevention of urinary tract infection in patients with indwelling catheter. Inno J Nur Health 4: 89-94.

\section{Citation:}

Singh M, Kumar S, Pareek S (2021) Impact of Planned Teaching Program on Staff Nurses Regarding Prevention of Urinary Tract Infection. Integr J Nurs Med Volume 2(3): 1-3. 